\title{
Synthesis of Zinc Oxide (ZnO) Nano Particles Using Sol Gel Method as Active Material on Gas Sensor
}

\author{
Slamet Widodo dan Tony Kristiantoro \\ Research Center for Electronics and Telecommunications Indonesian Institute of Sciences \\ PPET-LIPI, Kampus LIPI Jl. Sangkuriang Bandung 40135, Indonesia \\ Telp. : (022) 2504660, 2504661; Fax: (022) 2504659 \\ Email : slametwidodo50@gmail.com
}

\begin{abstract}
Gas sensor is needed to detect and the presence of gas, either for toxic gas or non toxic gas. The one of the important part in gas sensor instrument is the metal oxide. There are some ways to make metal oxide for sensing material of gas sensor; the one is sol-gel process. The purpose of this experiment is to make zinc oxide by sol-gel process. Zinc acetate dehydrate is dissolved in diethylene glycol and heated up to $130 \mathrm{OC}$ until a clear solution is obtained. After adding de-ionized water under vigorous stirring the resulting mixture is heated at $1800 \mathrm{C}$ for 2 hours. After drying at $4000 \mathrm{C}$ for 2 hours and annealing at $6000 \mathrm{C}$ for 1 hour, a yellow fine powder is obtained, which is identified by using XRD and SEM. From this observation, Zinc Oxide has been formed in nano size range, it is around 100 nanometer as the major phase with homology peak value of XRD between $\mathrm{ZnO}$ standard and product is 98 .
\end{abstract}

Keywords: Active sensing material, $\mathrm{ZnO}$, nano crystalline, sol gel, gas sensor.

\section{Introduction}

The toxic gas is very dangerous for human life, therefore we need tools that can monitor the gas content. Semiconductor sensor is a type of sensor that is inexpensive and easy to monitor gas. For sensitive parts of the gas sensors normally used compound semiconductor metal oxide ${ }^{1}$.

Sensitive gas sensors using metal oxide section has an important role in detecting some harmful pollutants such as carbon monoxide ( $\mathrm{CO}$ ) and hydrogen sulfide $\left(\mathrm{H}_{2} \mathrm{~S}\right)$. Thin plate-shaped sensor is widely used because of its small size, less energy consumption, and easy preparation $^{2}$.

One metal oxide compound that is widely used for semiconductor gas sensors are zinc oxide compound. There have been many experiments were carried out, and gases that can be detected for example gases alcohols such as ethanol and methanol gas ${ }^{3}$. There are several methods that have been used to produce the sensitive layer of metal oxide gas sensors as the basis, including the method of ball milling and sol-gel process. However, the method of ball milling, the metal oxide grains produced less reach nanometer size were compared using the sol-gel process. Therefore, the solgel process becomes more reliable method for use in the manufacture of metal oxide sensitive layer of nanometer-size ${ }^{4}$.

The sol-gel process have been had the advantage, ie the size of the particles that reach the surface of the nano-size and produced more uniform and flat, so that the adsorbed gas will be more and more. Additionally this sensor manufacturing costs are not too expensive ${ }^{5}$.

\section{Review of Literature}

The harsh characteristics, stable to temperature and chemical resistance. Typically, the structure of the oxide material is the crystalline required. Crystalline in this case means the same as in crystalline metals. The structure is repeated in a certain period and in three dimensions. To determine the crystalline quality of the material, we can use the X-ray diffractometer (XRD). Through observation of scanning electron microscope (SEM), the crystal can be viewed as a collection of granules. These large granules can be small in size. 
Crystallinity of the oxide material can be high if the large grains, and vice versa. The granules in growth stalled by another grain growth. Boundaries between grains in the material world is called the grain boundary. Grain boundaries is due to the growth of the crystal grains. If the crystal grains grow then met with another crystal grains of different crystal orientation of the grain boundary occurs. In a gas sensor material, grain boundaries is what took the role. Oxygen adsorption occurs at grain boundaries is due to the grain boundary surface energy higher than grains or crystals more easily diffuse gas and adsorbed onto the grain boundary regions ${ }^{6}$.

Sensors are devices used to convert a physical quantity into electrical quantities that can be analyzed with a particular electrical circuit. Almost all existing electronic equipment has sensors in it. At this time, the sensor has been made by the very small size of the order of nanometers. Very small size is very convenient use and energy savings ${ }^{7}$.

Gas sensor is a device that detects the quantity of a gas into an electronic scale. In gas sensors there are two main parts: the sensitive parts made of metal oxide and semiconductor parts. The working principle for the semiconductor gas sensor is based on the nature of the electronic charge change due to the presence of gas. For instance, oxygen gas, oxygen has free electrons, this causes the electrical conductivity properties of the vacuum ${ }^{7}$.

At room temperature, the oxygen adsorbed on all surfaces (including the surfaces of metal oxides). Oxygen molecules react with the electrons of the metal oxide and decrease the concentration of free electrons. In an environment with low levels of oxygen, oxygen species diffuses to the oxide material environment. Oxygen diffuses into the surface of the grain boundaries. So the more grain boundaries, the greater the probability of oxygen diffused and bound in the oxide material. That is, in the gas sensor, we need a crystal grains are small.

The oxygen diffuses into oxide materials due to differences in the concentration of oxygen levels. In thermodynamics, the chemical potential due to differences in the concentration of oxygen in the environment with oxygen in the oxide material which encourages oxygen diffuses into the oxide material ${ }^{8}$.

Gas detection principle of metal oxide semiconductor gas sensors rely on the ability of adsorption / desorption between the gas molecules with the surface. In the case of semiconductor gas sensors, all gas reaction process can be divided into five important stages, namely: the diffusion of reactants to the active region, the adsorption of reactants to the active region, the reaction on the surface, desorption of products from the active region, the diffusion of the product leaving the active region ${ }^{7}$.

\subsection{Sol-Gel Process}

The development of sol-gel process began in the 1880s. Various types of microfiltration membranes have been known so far, which is based on metal or carbon, but its application is limited to the size of the pores. The solgel process consists of several steps, among others: hydrolysis, condensation, gelation, ripening, drying, densification.

Sol-gel process is a wet chemical technique (chemical solution deposition) for the manufacture of a material (especially metal oxide) starting from a chemical solution that is part of the sol, or colloidal particles (sol for nanometer-sized particles) to the creation of a piece of gel. Precursor or starting material in the manufacture of metal oxides usually are metal alkoxides and metal chlorides, which then undergoes hydrolysis reaction and poly condensation reactions to form a colloidal sol, which is a system that consists of solid particles (particle size between 1-100 nanometers) are dispersed in the solvent.

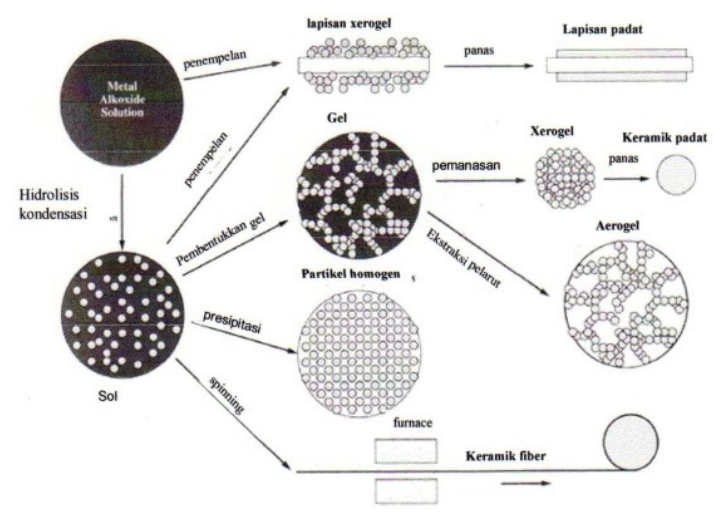

Figure 1: Sol-gel technology and products produced

Colloidal sol system can undergo further processing to form a ceramic material with a variety of forms, such as the soles can be coated on a substrate to form the film through the dip-coating or spin-coating. These insoles can also be formed into a gel system that is then dried 
and calcined (heated) produces a dense ceramic. If the gel is undergoing drying under super critical conditions, then the resulting material is an air gel.

Of the several stages of the sol-gel process, there are two general stages in the manufacture of metal oxides, namely hydrolysis and poly condensation. At this stage of hydrolysis (Figure 2), an attack of water molecule (nucleo philic attack), the oxygen atoms in the water, on the atom at the center of positive charge, which is generally in the form of metal.

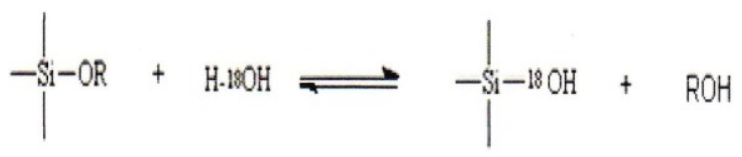

Fig 2: The reaction of alkoxide hydrolysis in compound

The hydrolysis process can be catalyzed by an acid or base in order reaction rate becomes faster. Part sol or colloidal particles are formed subsequent to the hydrolysis reaction. Part of this sol is a colloidal solid phase dispersed in a liquid phase. Hydroxy groups will be formed in the precursors that undergo hydrolysis, either with acid or base catalyst as in Figure 7 and Figure 4. As an example of precursors used are silicone compounds.
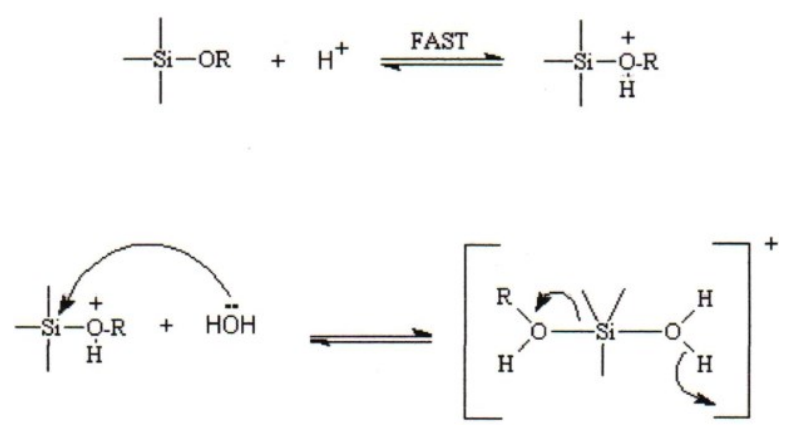

Fig. 3: hydrolysis reaction catalyzed by acid catalysts

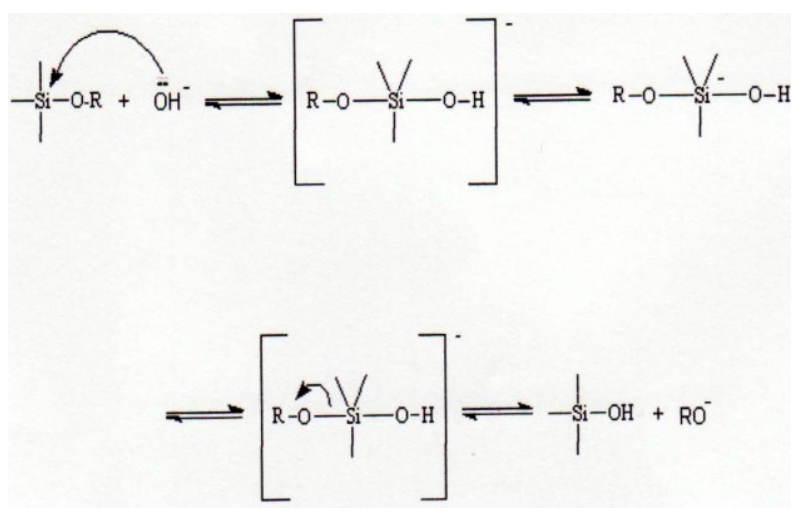

Figure 4: hydrolysis reaction catalyzed by the base catalysts

Hydroxy group formed to carry out attacks on other precursors or reactants are known as a condensation reaction (Figure 5)

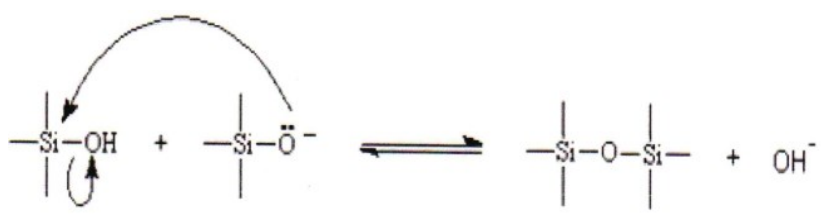

Fig. 5: The reaction of poly condensation

Increasing the viscosity of the solution indicates that the process of polymerization or condensation has occurred. By changing the charge on the surface of the particles (zeta potential) or an increase in the concentration of particles which are then followed by the agglomeration process, the gel will form part.

The sol-gel process is very lucrative and attractive for low cost and uses a low temperature so it is quite safe in the process, and can be easier to control in the determination of the chemical composition of the desired product. Sol-gel process can be used in the manufacture of ceramics, or as a means of making very thin films of metal oxides for various processes 8 .

\subsection{Zinc Oxide Nanoparticles}

Zinc oxide $(\mathrm{ZnO})$ has attracted the attention of the scientific community as a material future due to the nature of this materal is biocompatible and resistant to radiation. Pressure and room temperature, the crystal structure of $\mathrm{ZnO}$ are wurtzite (B4 type), as shown in figure 6 below ${ }^{9}$. 


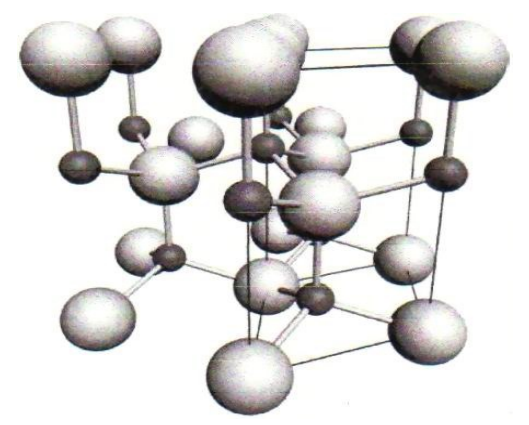

Fig. 6: hexagonal wurtzite structure of $\mathrm{ZnO}$.

Zinc oxide material is used for various applications, such as hydrogen sensors. That have been used are as hydrogen gas sensors in the fuel system of a starship. The advantages of this sensor is the ability to detect hydrogen at room temperature in the presence of air. In addition, the energy required is very small and lightweight as well weighing.

\section{Experiment}

The tools used in the experiments are the means glasses, crucibles, electric heating (hot plate), oven and furnace. While the characteristics of the test equipment crystals or powder is scanning electron microscope (SEM) and $\mathrm{X}$-ray Diffractometer (XRD).

The materials used consisted of distilled water / (deionized) $\mathrm{H}_{2} \mathrm{O}$, dietilene glycol (Merck, 99\%), Zinc Acetate dihydrate (Aldrich 99.99\%). A total of 1.52 grams of zinc acetate dissolved in Diethylene Glycol. Then the mixture is heated at a temperature of $130{ }^{\circ} \mathrm{C}$ to obtain a homogeneous solution. After that, ditambahakan $2 \mathrm{ml}$ of distilled water into the solution and stirred rapidly. Results of stirring and then heated at $180{ }^{0} \mathrm{C}$ for 2 hours. Fine grain white Zinc Oxide obtained after drying at a temperature of $400{ }^{0} \mathrm{C}$ for 2 hours and calcined at $600{ }^{\circ} \mathrm{C}$ for 1 hour. The way these work is simply described by Figure 3 .

Materials synthesized in the form of powder or crystalline form of tested characteristics and types of crystal structures were characterized by using XRD, while the size of the crystal is characterized by using SEM.

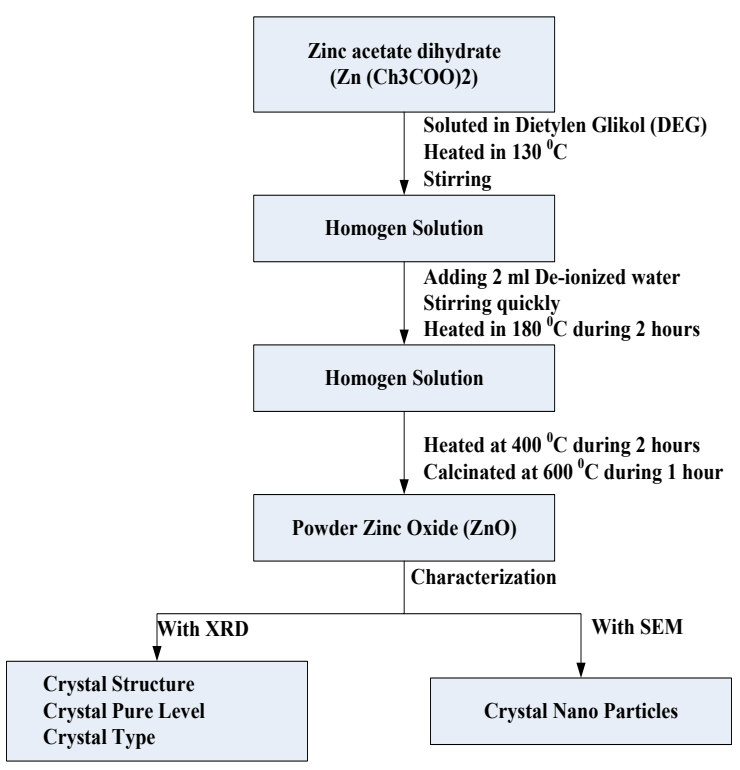

Fig. 7: Flowchart of the experimental manufacture of $\mathrm{ZnO}$.

\section{Results and Discussion}

\subsection{1 Preparation of Zinc Oxide by Sol Gel process}

Manufacture of gas sensors is the research that is being developed by many researchers in the world. Gas sensor material is a metal oxide compound is one important part of the gas sensors. The ability of the detection of a gas depends on the type of metal oxide compounds. A metal oxide has a certain sensitivity to a gas. The ability of a compound metal oxide adsorption is also influenced by particle size. The smaller the particle size of which is owned by the oxide metal compounds, the sensitivity will be higher. Therefore in this study is made of metal oxide compounds with nano-meter size. Many processes can be done to produce the metal oxide compounds. The sol-gel process is a process that have been most widely used with success rate is quite high, but it also was easy and fast way. The materials needed include free mineral water (de-ionized $\mathrm{H}_{2} \mathrm{O}$ ), diethylene glycol (DEG), zinc acetate dihydrate. Zinc acetate dihydrate was dissolved in diethylene glycol and heated at a temperature of 130 ${ }^{0} \mathrm{C}$ to obtain a homogeneous solution colorless. The reaction is as follows: 


$$
\begin{aligned}
& \mathrm{Zn}\left(\mathrm{CH}_{3} \mathrm{COO}\right)_{2} 2 \mathrm{H}_{2} \mathrm{O}(\mathrm{s})+\mathrm{HO}\left(\mathrm{CH}_{2}\right)_{2} \mathrm{O}\left(\mathrm{CH}_{2}\right)_{2} \mathrm{OH} \\
& \overrightarrow{\mathrm{Zn}(\mathrm{OH})}+\mathrm{HOOC}\left(\mathrm{CH}_{2}\right)_{2}{ }^{\circ}\left(\mathrm{CH}_{2}\right)_{2} \mathrm{COOH}+2 \mathrm{H}_{2} \mathrm{O}
\end{aligned}
$$

This initial stage is the stage of solvation (1). At this stage regardless acetate and zinc compounds formed dihidroxide. Once it is added demineralized water (deionized $\mathrm{H}_{2} \mathrm{O}$ ) into the solution and heated at $180{ }^{\circ} \mathrm{C}$ and then stirred rapidly for 2 hours. As a result of the addition of distilled water hydrolysis reaction (2) which generates $\mathrm{Zn}^{2+}$ cation and anion- $\mathrm{OH}^{-}$follow reaction:

$$
\begin{aligned}
& \mathrm{Zn}(\mathrm{OH})_{2}(\mathrm{aq})+2 \mathrm{H}_{2} \mathrm{O} \longrightarrow \mathrm{Zn}(\mathrm{OH})_{4}{ }^{2-}(\mathrm{aq})+ \\
& 2 \mathrm{H}^{+}
\end{aligned}
$$

The results obtained colloid dried using an oven at a temperature of $400{ }^{0} \mathrm{C}$. for 2 hours. This stage is the stage of drying to remove the bulk of the existing solvent and at the same polymerization process occurs further from the colloidal sol system and then produce a colloidal gel system called Xerogel. After drying for 2 hours, then made the final stage, the stage calcination at $500{ }^{\circ} \mathrm{C}$ for 1 hour.

At the time of calcination reaction polymerization complex is formed hydroxyl bridge "Zn_O- $\mathrm{Zn"} \mathrm{and}$ eventually turned into $\mathrm{ZnO}$ (3) according to the reaction:

$$
\begin{aligned}
& \mathrm{Zn}(\mathrm{OH})_{4}{ }^{2-}(\mathrm{aq}) \longrightarrow \mathrm{ZnO}(\mathrm{s})+\mathrm{H}_{2} \mathrm{O}(\mathrm{g})+ \\
& 2 \mathrm{OH}^{--}
\end{aligned}
$$

Also a phase transition occurs from a liquid to a solid and removal of volatile fractions or remaining solvent and other compounds produced by side reactions, such as $\mathrm{H}_{2} \mathrm{O}$ and $\mathrm{OH}^{-}$.

\subsection{2 Particle Characterization of Zinc Oxide (ZnO)}

To characterize the resulting $\mathrm{ZnO}$ particles. In addition to using XRD, also the tool used electron microscopy (SEM) to determine the crystal morphology of the particles, such as crystal size and uniformity of the $\mathrm{ZnO}$ crystal.

Figure 10 shows the results of XRD characterization of $\mathrm{ZnO}$ powder. Through the comparison of the results of the synthesis of $\mathrm{ZnO}$ peak pattern with the standard peak pattern indicates a fairly large similarities with the value of 98 , it can be believed that the resulting powder is $\mathrm{ZnO}$ powder Which has a hexagonal crystal structure wurzit.

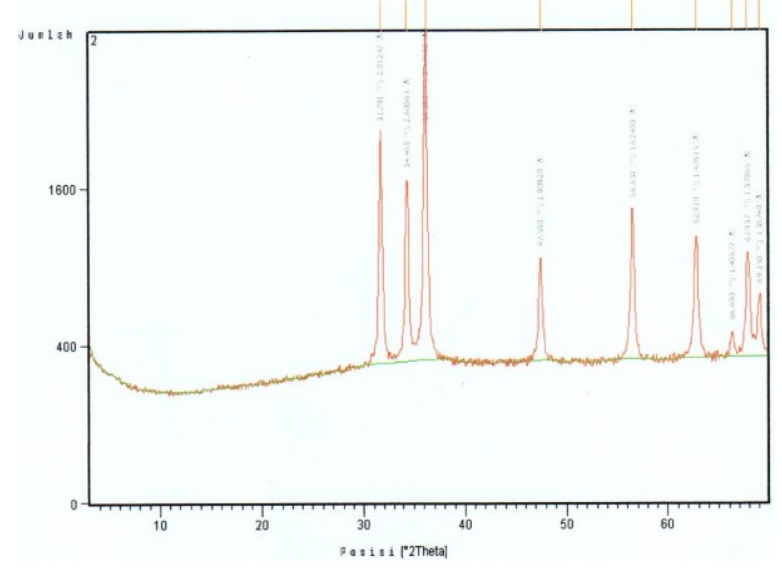

Fig. 4.1: Results of powder XRD Zinc Oxide

Table 4.1 Zinc Oxide powder XRD parameters compared to the standard (JCPDS 36-1451)

\begin{tabular}{|ccc|}
\hline ZnO & Results & JCPDS 36-1451 \\
\hline $2 \theta$ & d-spacing/ $\AA$ & d-spacing $/ \AA$ \\
\hline 31.7914 & 2.81247 & 2.8143 \\
34.4584 & 2.60065 & 2.6033 \\
36.2818 & 2.47402 & 2.4759 \\
47.5882 & 1.90928 & 1.9111 \\
56.6305 & 1.62400 & 1.6247 \\
62.9100 & 1.47615 & 1.4771 \\
\hline \multicolumn{3}{|}{} \\
\hline
\end{tabular}

Table 4.2 Results of identification purity Zinc Oxide

\begin{tabular}{|llllll|}
\hline \multicolumn{4}{|l}{$\begin{array}{l}\text { Standard Value Compound Friction } \\
\text { Code }\end{array}$} & Scale & Formula \\
\hline $01-089-$ & 98 & Zinc Oxide & 0.000 & 0.900 & $\mathrm{ZnO}$ \\
0510 & & & & & \\
\hline
\end{tabular}

In figure 8 can be seen the value and shape of the peaks of the XRD results for $\mathrm{ZnO} .2$ theta peaks of the $\mathrm{d}$-spacing values are then compared with the d-spacing of nlai standard. Can be seen in Table 4.2 that the values are relatively similar. Figure 4.2 shows the comparison of the peaks that appear in the measurement. Measurements were taken at $2 \theta$ from 30 to 70 . The peaks of $\mathrm{ZnO}$ synthetic results (green / top) shows significant similarity with the standard (red / bottom). From the measurement data, the peak value of the similarity comparison between the results of the 
synthetic standard $\mathrm{ZnO}$ is large enough that 98 . Then the sol-gel process has a fairly high success rate for the synthetic Zinc Oxide.

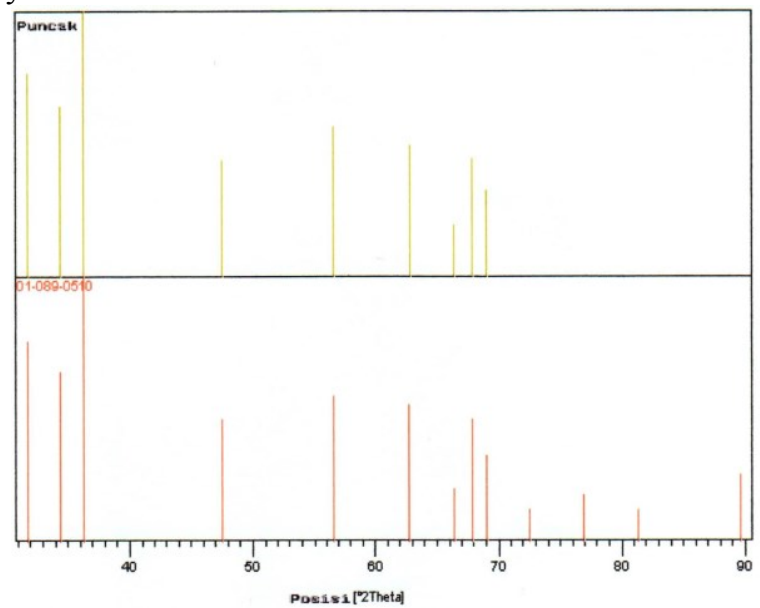

Fig. 8: Plot of the ratio between the standard $\mathrm{ZnO}$ (red / bottom) with the synthesized $\mathrm{ZnO}$ (green / upper)

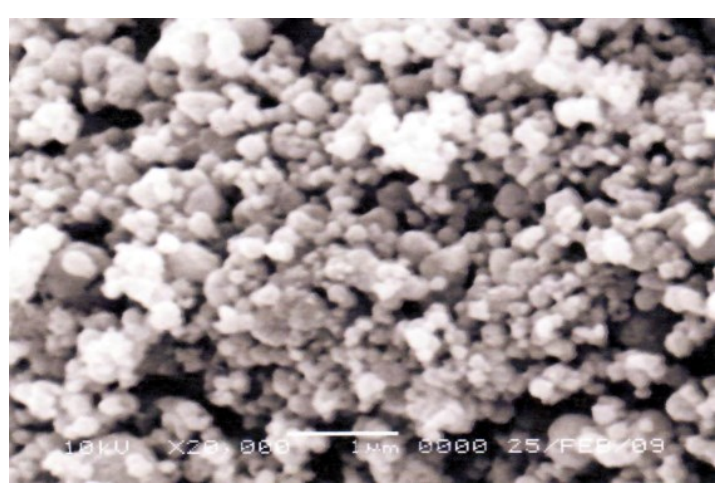

Fig. 9: SEM Photo synthesized $\mathrm{ZnO}$ powder with a magnification of 20,000 times

To determine the size of the particle Zinc Oxide synthesis results, the shooting is done with SEM. Figure 9 is the result characterization using SEM showing the morphology of $\mathrm{ZnO}$ powder with a magnification of 20,000 times.

It can be seen from the scale on the photo where the white line represents footage $1000 \mathrm{~nm}$. The smallest particle size of $\mathrm{ZnO}$ can be achieved by the sol-gel process is less than $100 \mathrm{~nm}$. From Figure 9 can be seen that there are some particles whose size has reached less than $100 \mathrm{~nm}$. In addition to images with a magnification of 20,000 times, done well capturing images with SEM with a magnification of 40,000 times. Magnification is 40,000 times the maximum limit of magnification SEM instrument used in this study. The images obtained less sharp. However, from Figure 10 below we can see the average particle size of $\mathrm{ZnO}$

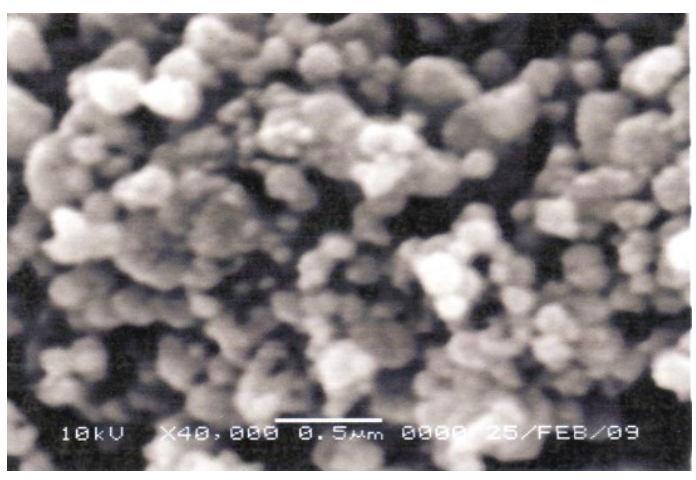

Fig. 10: SEM photos of $\mathrm{ZnO}$ powder synthetic results with magnification 40,000 times

It can be seen that for a magnification of 40,000 times, the white line represents scale of $500 \mathrm{~nm}$. Some parts of the $\mathrm{ZnO}$ particles have already reached a size less than $100 \mathrm{~nm}$.

\section{Conclusions}

From the research that has been done, it is concluded as follows:

Powder Zinc Oxide $(\mathrm{ZnO})$ as the main phase can be synthesized through sol-gel process with the use of Zinc Acetate Dihydrate, Diethylene Glycol and de-ionized $\mathrm{H}_{2} \mathrm{O}$ with a peak value of $2 \theta$ similarity of 98 .

Zinc oxide powders obtained by the sol-gel process has reached the value of the size scale of 100 nanometers, with the smaller size (nanometers), to get the surface area increases, so that the more sensitive gas sensors.

\section{References}

1. Mitra, P., et al., 1998, ZnO Thin Film Sensor, Matter Lett., 35, 33-38.

2. Abbasour-Sani, E., et al., 2007, Application of $\mathrm{SnO}_{2}$ Nano-Powder on MEMS Type Gas Sensors, Sensors \& Transducers Journal, Vol. 78, pp. 1108-1113.

3. Cheng, X.L., et.al., 2004, ZnO Nanoparticulate Thin Film: Preparation, Characterization and Gas-Sensing Property, Sensor Actuators, B 102, 248-252.

4. Wiranto, G., Sugandi, G., Hermida, I.G.P., Widodo, S., Supriyanto, E., 2008, Pengembangan Metode Baru Dalam Rancang Bangun Sistem Sensor Berbasis MEMS Untuk Monitoring Pencemaran Lingkungan, Pemaparan Hasil Litbang Ilmu Pengetahuan Teknik IV, B113-118. 
5. Lieznerski, B., 2004, Thick Film Gas Microsensors Based on Tin Dioxide, Bulletin of the polish academy of sciences, Technical Sciences, 52, (1), 37-42.

6. Nunung, 2008, Pengembangan Sensor Gas Hidrogen Sulfida Berbasis Reagen Kering Timbal Asetat, http://one.indoskripsi.com/content/pengembangansensorgas-hidrogen-sulfida-berbasis-reagen-keringtimbal-asetat.

7. Hildenbrand, J., 2003, Simulation and Characterisation of a Micromachined Gas Sensor and Preparation for Model Order Reduction, Diploma Thesis, Albert Ludwig University Freiburg Germany.

8. Wibowo, R.A., 2008 Aplikasi Material Oksida Sebagai Gas

Sensor, http://energisurya.wordpress.com/2007/04/23/aplikasimaterial-oksida-sebagai-gas-sensor

9. Jagadish, C., \& Pearton S., 2006, Zinc Oxide Bulk, Thin Films and Nanostructures, Elsevier Limited, USA. 